\title{
Comparative Study on the Governance of SetoNaikai in Japan to Bohai Sea
}

\author{
Li yuqiao *, Wang Yan' an, Yin Yiwen, Sun Wenchun \\ School of Government Management, Beijing Normal University, Beijing 100875
}

\begin{abstract}
This paper explores Japan's successful experience in controlling SetoNaikai and discusses the enlightenment to China's governance of Bohai Sea. In 2006, the National Development and Reform Commission launched the "Bohai Sea Environmental Protection General Plan" and also announced the failure to implement the "Bohai Sea Clean Sea Action Plan" in the past five years. Similarly, there has been similar pollution in SetoNaikai of Japan. But after 10 years of treatment, it has been quite effective. Through the research methods of international cooperation and exchange, expert interviews and literature analysis, the current situation and existing problems of governance of Bohai Sea are mastered. This paper selects SetoNaikai as the research object, compares the environment and policies between China and Japan and constructs countermeasures and mechanisms of China's environmental governance of Bohai Sea.
\end{abstract}

\section{Introduction}

In the report of the 18th National Congress of the CPC, it was the first time to explicitly propose to build a strong ocean power. The report called for "improving the development capacity of ocean resources, developing the ocean economy, protecting the marine ecological environment, and firmly safeguarding the national marine rights and interests." This is the first time that our party has made a systematic exposition of the national marine development strategy in the form of a report of the National Congress, which points out the direction for our country to introduce the national marine strategy in the future. Among them, the most obvious problem is the marine environment. How to minimize or avoid the damage to the environment caused by economic development and how to coordinate the sustainable development of economy and environment to achieve a harmonious and win-win situation have become an urgent social problem to be solved.

However, since the late 1970s, with the rapid development of the surrounding economy in recent years, the marine environment has been seriously polluted and destroyed, turning the " park" into a " sewage field", and wild fish and shrimp have almost disappeared. The negative externalities produced have a negative impact on the surrounding environment and residents, especially in the middle and late of 1990s. According to the monitoring and evaluation results for many years, the pollution scope in the nearshore area of Bohai Sea is expanding. The polluted area of Bohai Sea was about $20 \%$ in 1992, while the polluted area of Bohai Sea was about $40 \%$ in 1998. After several years of treatment, the area of Bohai Sea that did not meet the clean sea water quality standard was about 20,000 square kilometers in 2006, accounting for $26 \%$ of the total area of the Bohai Sea. A total of 11 red tides occurred, with a cumulative area of 2,980 square kilometers. The pollution situation is still serious. The polluted sea areas are mainly concentrated in the coastal areas of Liaodong Bay, Bohai Bay and Laizhou Bay. The main pollutants are inorganic nitrogen, active phosphate and petroleum (state oceanic administration, 1990 - 2006). Since 2001, China has started to control the Bohai Sea problem, but it has achieved little or even worse results. The reasons are that management is intersected and multiheaded, which leads to unclear rights and responsibilities, and the occurrence of the dilemma of " the marine department does not go ashore, the environmental protection department does not go into the sea, no matter how to control the sewage discharge, the control of the sewage discharge cannot be controlled".

\section{Literature review}

There are three basic frameworks for foreign traditional public environmental governance, including Harding's Tragedy of Public Places, Prisoner's Dilemma and Collective Behavior Theory. From the theory of collective behavior, Olsen holds the view that" unless there is a relatively small number of people in a group, or unless there is coercion or some other special means to urge individuals to act for their common interests. Rational individuals seeking their own interests will not act to realize the interests of their common living groups. ${ }^{[1}$ "Unless public output is related to personal interests, rational" economic man" will not contribute personal strength. The three theoretical frameworks all have the same pattern, which is, hitchhiking problem. If the temptation of hitchhiking dominates the decision-making process, there will be no collective interest. However, if some people provide public goods while others hitchhike, then the supply of collective interest will not reach Pareto 
Optimality. Traditional solutions include centralized power system, privatization and collective actions of independent organizations. Coase believes that privatization can define property rights ${ }^{[2]}$, internalize external costs ${ }^{[3]}$, how people benefit and how they suffer in order to improve the efficiency of resource allocation ${ }^{[4]}$. The collective action theory of independent organizations represented by Ostrom has become an effective alternative to the two traditional methods. Ostrom's autonomous organization includes eight design principles. First, the border is clearly defined. Second, occupation and supply rules are consistent with local conditions. Third, the arrangement of collective choice. Fourth, supervision. Fifthly, graded sanctions. Sixth, the conflict resolution mechanism. Seventh, minimum recognition of the right to organize. Eighth, decentralized enterprises. Ostrom's main contribution is to provide a theoretical analysis framework for new public governance. ${ }^{[5]}$

More and more scholars in China have realized the importance of citizens' full participation in autonomous public governance to public environmental governance. The main body of public governance includes non-profit organizations, voluntary organizations, non-governmental organizations and various associations, which embody the importance of public governance in which people participate extensively. Yang Zhenjiao and others ( 2016 ) think that NGO ( non-governmental organization ) should be fully utilized and the participation of the masses should be expanded to carry out marine environmental governance from the perspective of governance, and move from governance to good governance in order to put forward solutions to marine environmental governance ${ }^{[6]}$. Song Danying (2017) puts forward the role of NGO in environmental protection. From the perspective of environmental protection in tourist cities, this paper studies the positive role played by environmental NGO in marine environmental protection. Through the construction of a three-party game model of enterprises, government and environmental non-governmental organizations ( NGO ) that deal with the environment ${ }^{[7]}$, Liu Suxia ( 2017 ) holds the view that the best strategies of all parties are the cost of pollution control of enterprises, social awareness of the environment, the government's punishment and subsidy for pollution control. Wang Qi (2002) and others believe that the government needs to clarify its functions in marine environmental governance. Active participation and appropriate intervention in the process of governance are important guarantees for effective governance of the marine environment. ${ }^{[9]}$

\section{Comparative study on the governance of SetoNaikai and Bohai Sea}

\subsection{Comparison of natural conditions}

Similarly, as a semi-enclosed inland sea in the northwest Pacific Ocean, Bohai Sea and SetoNaikai also have many identical or similar places. Both are located in densely populated industrial zones, with similar climate and similar environmental problems successively. By other's faults, wise men correct their own. By learning from Japan's successful experience in controlling SetoNaikai for decades and combining with the characteristics and specific problems of the Bohai Sea, we will be able to find a practical and effective way to control and finally solve the pollution problem in the Bohai Sea.

Table 3 - 1 Comparison of natural conditions (As shown in Table)

\begin{tabular}{|c|c|c|c|c|c|c|c|c|c|c|}
\hline $\begin{array}{c}\text { Similarities } \\
\text { and } \\
\text { differences }\end{array}$ & $\begin{array}{c}\text { Sea } \\
\text { area } \\
(\mathrm{km} 2)\end{array}$ & $\begin{array}{l}\text { Land } \\
\text { area } \\
(\mathrm{km} 2)\end{array}$ & $\begin{array}{c}\text { Ratio } \\
\text { of sea } \\
\text { area to } \\
\text { land } \\
\text { area } \\
\end{array}$ & $\begin{array}{c}\text { Seaward } \\
\text { river }\end{array}$ & $\begin{array}{c}\text { Island } \\
\text { number }\end{array}$ & $\begin{array}{c}\text { Sealing } \\
\text { property }\end{array}$ & Entrance & $\begin{array}{c}\text { Average } \\
\text { depth of } \\
\text { seawater } \\
\text { ( m) }\end{array}$ & $\begin{array}{c}\text { Precipit } \\
\text { ation } \\
(\mathrm{mm})\end{array}$ & $\begin{array}{c}\text { Administr } \\
\text { ative } \\
\text { division }\end{array}$ \\
\hline SetoNaikai & 21400 & 9500 & 2.25 & $\begin{array}{c}21 \\
(620)\end{array}$ & 525 & $\begin{array}{l}\text { Semi - } \\
\text { closed, three } \\
\text { exits }\end{array}$ & $\begin{array}{c}30 \text { million } \\
\text { accounts for } \\
25 \% \text { of the } \\
\text { country }\end{array}$ & 37.3 & $100-1400$ & $\begin{array}{c}11 \\
\text { prefectures }\end{array}$ \\
\hline Bohai Sea & 95000 & 134000 & 0.71 & 40 & $\begin{array}{c}\text { 3Table } 3 \text { - } 1 \\
\text { Comparison of } \\
\text { natural } \\
\text { conditions (As } \\
\text { shown in } \\
\text { Table) } \\
0\end{array}$ & $\begin{array}{l}\text { The inland } \\
\text { sea, only } \\
\text { one outlet is } \\
\text { connected to } \\
\text { the yellow } \\
\text { sea. }\end{array}$ & $\begin{array}{l}240 \text { million } \\
\text { accounts for } \\
20 \% \text { of the } \\
\text { country }\end{array}$ & 18 & $500-600$ & $\begin{array}{c}\text { Three } \\
\text { provinces } \\
\text { and one } \\
\text { city } \\
13 \text { cities }\end{array}$ \\
\hline
\end{tabular}

\subsection{Comparison of environmental evolution and pollution sources between SetoNaikai and Bohai Sea}

Similar to the Bohai Sea, Japan's SetoNaikai, as a semiclosed inland sea, was once polluted seriously. In the Second World War, the region of SetoNaikai was an important base of heavy industry and military industry in Japan. After the defeat, Japan, which had abandoned everything but prosperity, made every effort to develop its economy. Large-scale joint enterprises of steel, chemistry, automobiles, shipbuilding, petroleum and petrochemicals began to concentrate on the coast. The coast of SetoNaikai became the most important industrial base, with production capacity accounting for more than $40 \%$ of the country. Later, as the rear area of the US army, the region supported two wars in North Korea and Vietnam successively, which made the environmental pollution and ecological damage in SetoNaikai more serious. 
Table 3 - 2 Comparison of applicable polluted conditions

\begin{tabular}{l}
\hline SetoNaikai pollution in Japan \\
\hline Serious water pollution \\
Reclamation out of control \\
Frequent red tide \\
Serious oil pollution in sea area \\
Nuclear pollution caused by dropping atomic \\
bombs is serious
\end{tabular}

The causes of environmental pollution in SetoNaikai and Bohai Sea in Japan are basically the same, which are caused by factors such as the development of industrial industry and the expansion of urban population. The pollution in SetoNaikai mainly includes pollution of marine environment caused by ships and related operations, pollution of coastal engineering construction projects to marine environment, pollution of marine engineering construction projects to the marine environment, pollution of marine environment by landbased pollutants, marine pollution caused by marine dumping of wastes, excessive reclamation and etc. The types of pollution mainly include water pollution, oil pollution, red tide, reclamation, and environmental damage caused by fragile ecosystems.

The pollution of Bohai Sea mainly includes pollution of marine environment by land-based pollutants, oil spill, dam building and sluice construction in the upper reaches of rivers entering the sea, pollution from mariculture, marine pollution caused by marine dumping wastes and pollution caused by ships and related operations to the marine environment, among which the first four items are the main factors of environmental changes in the Bohai Sea. The types of resulting pollution include water pollution, oil pollution, red tide, and fragile ecosystems.

\subsection{Comparison of economic industries}

SetoNaikai in Japan was an emerging industrial zone in Japan after World War II. Chemical, iron ore, oil and other industries in Setouchi's industrial areas, known as "heavy and thick growing" industries, began to develop significantly before the 1970 s, accounting for $40 \%$ of Japanese output. The transition is from the 1970s to the transport machinery manufacturing industry and electrical products manufacturing industry, especially the "light, thin and short" industry.

The region of Circum-Bohai Sea is economically developed, with gross national product accounting for nearly one-fourth of the country's total. The region of Circum-Bohai Sea is the base of heavy industry and chemical industry in China, forming a comprehensive industrial belt of Beijing-Tianjin-Hebei dominated by petrochemical, iron and steel metallurgy, and mechanical and electronic industries, forming a Shandong Peninsula Industrial Belt dominated by light and heavy industries such as electronics, machinery, petrochemicals and light textile and forming Liaodong Peninsula Industrial Belt, which is dominated by heavy machinery, shipbuilding, chemical industry and ultra-heavy industry. Besides,

\author{
Bohai Sea pollution in China \\ Heavy pollution near the coast \\ Reclamation project \\ Frequent red tide \\ Oil pollution and oil spill risk \\ A sharp drop in runoff into the sea
}

Wetland area around Bohai sea shrinks

Shanxi and Inner Mongolia are gradually becoming the heavy energy centers. In addition, mariculture of Bohai Sea occupies an important position in our country, accounting for $40.9 \%$ of the total national output.

Through the evolution of natural conditions, industrial economy and environmental pollution of SetoNaikai in Japan and Bohai Sea in China, we can see the similarities between SetoNaikai and Bohai sea in the above three aspects, namely semi-closed inland sea, administrative trans - regional and dry climate. Land-based pollution is one of the important pollution sources, and the main factor is economic development. What's more, the industry is dominated by heavy chemical industry and the population density is very high.

In terms of natural conditions, SetoNaikai has more estuaries than Bohai Sea, more rivers flowing into the sea and deeper seawater. Reefs in SetoNaikai are more widely distributed than Bohai Sea, and seawater flow and tide are stronger than Bohai Sea, and there is more precipitation at the same time. Therefore, SetoNaikai has stronger ability to slow down pollution. In terms of economy, the population base around Bohai Sea is large, and domestic sewage discharge is relatively serious. The industry is dominated by heavy chemical industry and mariculture occupies a large proportion in China. However, the transformation and relocation of heavy industry in Seto, Japan gradually formed a "light, thin and short" industrial pattern in the 1970s. Bohai Sea is still dominated by heavy chemical industry and mariculture, and industrial landbased pollution is higher than that of Japan. There are many inland sea islands in Japan and ports there are relatively scattered. But Bohai Sea owns few islands, in which natural ports are relatively concentrated, and marine pollution discharge is increased. In short, Bohai Sea is relatively closed in natural and economic aspects, with a high proportion of heavy chemical industry and relatively concentrated ports, which all increase environmental pollution. Thus, the difficulty of governance is greater than that of SetoNaikai.

\subsection{Comparison of governance methods}

At present, China mainly adopts centralized governance mode, but Japan adopts top-down central linkage mode. Publicity and education are the main tasks and civil organizations are also fully mobilized. What's more, participation of people is expanded and more and more people are mobilized to carry out supervision. At the same time, a more rapid response mechanism to special situations is formed. After ten years of governance, the government-led people's autonomy has achieved quite a 
lot. Although Bohai Sea is also under centralized governance, there are multiple levels of management overlapping, resulting in distortion of information transmission, loss of efficiency and reduction of execution capacity. In addition, it does not fully mobilize the active participation of the public, lacks the popularization and education of relevant knowledge and is short of the participation and support of the public. Besides, it has a slow response mechanism to various types of illegal enterprises, and lacks the effective supervision of the masses and the media. At the same time, the corresponding lack of laws has not played an effective deterrent and restriction mechanism.

\section{Discussion and summary of Seto's successful governance experience}

\subsection{Discussion of successful experiences}

For the polluted environment, it is necessary to control pollution under the centralization of power in the "Ritan" mode. Japan's success in controlling Seto is to adopt the linkage method of central planning before autonomy. The central government regulates the supply of funds through legislation. Daily implementation is based on autonomy, through hierarchical sanctions, participation in the formulation of rules, participation in supervision and etc.

\subsubsection{Governance under centralized power}

Seto's successful experience in environmental governance is as follows. Firstly, "Ritan" is the main central government's centralized system for reform, the local linkage policy and the direct reporting system to the cabinet prime minister. Local and central coordination mechanisms have been formed in trans-regional areas, with the environmental protection department as the main body, and implemented with the personal intervention of the highest executive head of the government. The mechanism for trans-regional implementation is mainly a conference system for environmental protection attended by governors of 13 prefectures and 5 counties and mayors, and a reporting system for local environmental protection plans to cabinet prime ministers. Secondly, the hierarchical sanction system is formulated by the central government. In order to organize the implementation of various provisions of the law, SetoNaikai Environmental Protection Special Measures Law has formulated specific cross-regional implementation mechanisms, legislating, perfecting the marine management system and legal implementation mechanisms, clarifying the responsibilities of the central and local governments at all levels, performing their duties up and down, and working together to jointly strengthen marine environmental governance and protecting the marine "light, thin and short" industry. Environment and marine ecology, which is the most basic and main experience. ${ }^{[11]}$ Thirdly, a permit system is established to clearly define the access system and marine development activities that have adverse impacts on the marine environment and marine resources are all restricted so that the possession and supply of resource units can be balanced.

\subsubsection{Linkage governance with local participation}

Apart from the top-down centralized system, a local autonomous system has also been established. Firstly, the supervision of public participation. In the daily management, in order to effectively monitor the pollution discharge situation, the main monitoring points are established, and local fishermen are fully mobilized to participate in the supervision and reporting in order to effectively save the supervision cost. Secondly, perfecting the matching fund guarantee and the joint mechanism between the central government and the local government. Thirdly, improving the organization system of environmental research and environmental protection in inland seas. Through education and publicity, raising awareness of environmental protection and enabling people to actively participate in the protection of the marine environment and establishing an environmental research base in the area to carry out continuous research and control of the marine environment. ${ }^{[12]}$ After many years of treatment, the environment in SetoNaikai in Japan improved in the 1980s and the water quality has basically returned to good condition.

\subsection{Pollution control suggestions in Bohai Sea}

Firstly, a centralized system of the central government and a responsibility system for governors are respectively established. First of all, we should establish and perfect laws and regulations on environmental governance of Bohai Sea, establishing a separate special act on environmental governance of Bohai Sea, especially establishing the control and restoration of the total amount of pollution of Bohai sea and its license rules and regulations, clearly defining the funds, strengthening the connection and operability among laws, regulations, and plans so that the laws can be implemented. ${ }^{[14]}$ The governor shall assume the responsibility system, and the governance results shall be reported directly to the central government.

Secondly, public supervision and autonomy. Improving the environmental monitoring mechanism of Bohai Sea and the construction of the main body, establishing the environmental monitoring mechanism of Bohai Sea composed of enterprises, fishermen, the public and the government, and also establishing environmental research and NGO environmental protection organization of Bohai Sea to form an independent Bohai Environmental Research Institution funded by enterprises and the government ${ }^{[15]}$, which can strengthen public environmental protection and public nuisance education, enhance public participation in environmental protection, and form a top-down and bottom-up linkage mechanism.

Thirdly, the border is clearly defined. Issuing emission permits to enterprises with a certain economic scale, closing down or relocating enterprises with small scale and heavy pollution, delimiting the sea area under the 
jurisdiction of enterprises with emission permits, and establishing enterprise federations for enterprises with emission qualifications. The federations are responsible for the environmental assessment, pollutant total amount control and emission permit trading system of Bohai Sea and the discharge system of sewage into the sea based on the environmental protection law. At the same time, a permit system will be issued to fishermen to determine their fishing areas and scale.

Fourthly, graded sanctions. The enterprise association will carry out internal sanctions. For non-serious acts, it will carry out internal sanctions. For more serious cases and enterprises that frequently violate regulations, it can carry out hierarchical sanctions through government and legal procedures.

Fifthly, minimum recognition of the federation of enterprises. Fully recognizing the rights and obligations of the federation of enterprises. The local environmental protection and marine system should serve the federation of enterprises and give it some support. The enterprise federation shall assume responsibility for the three provinces and one mayor, and the three provinces and one mayor shall assume responsibility for the central government.

Sixthly, coastal enterprises are integrated and the industrial structure is gradually adjusted. Small enterprises with low yield and high pollution are closed or relocated, and large enterprises with high yield and large scale are integrated to form a scale, gradually adjusting the industrial structure, establishing a pollution prevention measure system based on industrial upgrading and transformation, and fundamentally reducing land-based pollution starting from the industrial structure.

Seventhly, the financial investment mechanism for autonomy and ocean restoration is established and perfected and a comprehensive governance system with the goal of governance effect is established. The system should be based on legislation, guaranteed by autonomy and monitoring investment and also based on total amount control and compensation for restoration and public participation.

\section{Conclusion}

The governance of Bohai Sea can partly refer to Japan's successful model and adopt a combination of centralized power system and autonomous governance. In terms of centralization of power, the establishment of the Bohai Sea Marine Protection Law and the determination of punishment standards and total emissions can be determined by local experienced individuals and organizations in a unified way. The central government carries out random inspection of marine water quality from time to time, implementing the responsibility system of governors, who are directly responsible for the results of the inspection. In daily management, the establishment of a coastal enterprise management association, including coastal enterprises with a certain economic scale and with emission qualifications, forms an autonomous organization. Members of the Federation are responsible for the coastal emissions under their jurisdiction, and limit the emissions and total emissions of each enterprise, which can determine the emissions of each enterprise through regular and limited daily emissions, as well as by limiting the specifications of the pipelines to be discharged and the standards for the discharge of waste water. Enterprises implement the responsibility system for areas delimited by the coastal areas, and fishermen can supervise enterprises' illegal emissions. Any enterprise that violates the regulations can be divided by the Federation into fines and graded sanctions. In serious cases, they can revoke their emission permits or go through legal procedures.

\section{References:}

1. Mansel Olsen, the logic of collective action, new knowledge sanlian publishing, 1995

2. R. Coase. Property rights and institutional change $[\mathrm{M}]$. Shanghai: Shanghai people's publishing house,2003.

3. Demsetz: 《Toward a Theory of Property Rights 》 American Economic Review, 57 (May ,No.2):347359

4. Furubotn,E.G.\&Pejovich,S.1972.Property rights and economic theory:a survey of recent literature.Journal of Economic Literature, 10(4)

5. Eleanor ostrom, public affairs governance: the evolution of collective action systems, Shanghai sanlian press, 2000

6. Yang zhenjiao, sun xuemin, luo lingyun. Research on the policy participation of environmental ngos in China's Marine environmental governance [J]. Marine environmental science, 2016, 35(3):444-452.

7. Song danying, song hongjuan, song ting. The role and inspiration of ngos in Marine environmental protection in tourism cities -- a case study of hainan "blue ribbon" Marine protection association [J].

8. liu suxia, zhu yingming, du guangqi. Game analysis of enterprises, governments and environmental ngos in environmental pollution control [J]. Environmental pollution and prevention, 2017, 39(5):574-577.

9. wang qi, zhang dexian, he guangshun. Analysis of government behavior in Marine environmental management [J]. Ocean bulletin, 2002,(06):60-67.

10. zheng miaozhuang, liu yan, qiu wanfei. On the modernization of China's Marine ecological environmental management system $[\mathrm{J}]$. Environment and sustainable development, 2017, 42(01):37-40.

11. xu xiangmin, kong xiaoming; The successful experience of Japan's setoyo special treatment law on environmental protection in inland seas [J]. China ocean law review, 2007-1

12. Stone broken;Setouchi neihai governance $[\mathrm{N}]$ semimonthly: 2006-08

13. Ma caihua, you kui, gao jintian;Setoyo setouchi's enlightenment to China: journal of ocean university of China (social science edition) [J].2012-5

14. Li haiqing, comparative study on environmental 
legislation in Bohai Sea and seto inland sea, Marine environmental science [J].2011

15. Li shuwen, causes and countermeasures of pollution problems in the bohai rim, economic research guide [J]. 2007(3):159-161 